\title{
DA ANTROPOLOGIA COMO CORRIDA DE TORA'
}

\section{ANTHROPOLOGY AS A LOG RACE}

\author{
Julio Cezar Melatti*
}

$\mathrm{Eu}$ gostaria de começar agradecendo o convite para participar deste Seminário. Dizer da minha satisfação proporcionada pelo convite e constatar como se multiplicou o número de pesquisadores dedicados ao estudo da cultura e dos problemas Timbira. 0 estudo dos Timbira começou com Curt Nimuendaju, que chamou a atenção para a importância da pesquisa entre os Timbira para a discussão de certas questões no âmbito da antropologia. Curt Nimuendaju era alemão, nasceu em 1883 e chegou ao Brasil em 1905. Ele veio interessado em estudar índios. Na Alemanha, era um trabalhador da fábrica de lentes Zeiss, que fazia lentes para óculos, para telescópios, para binóculos etc. É uma fábrica que existe até hoje e possui várias filiais. A fábrica de lentes
Zeiss - não sei por que e, evidentemente, as fábricas de hoje não têm mais isso - mas o fato é que a fábrica de lentes Zeiss tinha uma biblioteca. E Nimuendaju estudava na biblioteca textos sobre índios. Com isso, ele se interessou muito por esse tema, e veio para o Brasil à procura de índios para conhecer. Desde 1905, quando chegou ao Brasil, até 1945, quando morreu, passou quarenta anos aqui e praticamente todos os anos visitava uma aldeia indígena em partes diferentes do Brasil. Nos anos 1920, começou a visitar os Canela da Aldeia do Ponto, e outros Timbira também. Ele escreveu um livro grande sobre os Canela, denominado Os Timbira Orientais (publicado em 1946, um ano após seu falecimento); outro sobre os Apinajé (1939) e outro so-

\footnotetext{
* Doutor em Antropologia pela Universidade de São Paulo (USP). Entre 1969 e 1994 foi professor na Universidade de Brasília (Brasília/DF/BR). Em 1997 pós-doutorou-se pela Smithsonian Institution nos Estados Unidos. Professor Emérito, Universidade de Brasília (UNB).juliomelatti@gmail.com.

1. Palavras proferidas no VI Seminário Timbira, "Povos Timbira: Educações e Conhecimentos”, ocorrido no Centro Timbira PënxwyjHëmpejxà (Carolina - MA) entre os dias 15 e 17 de dezembro de 2015. 0 Seminário foi organizado pelas seguintes instituições: PPGSOC (UFMA); Timbira Research and Education Foundation (USA); NEAI (UFT); FAPEMA, com apoio da Associação Wyty Cate; CTI; CTEPPH. Filmagem do original: André Demarchi. Transcrição e revisão geral: André Demarchi, Odilon Morais, Odair Giraldin.
} 
bre os Xerente (1942). E mais adiante ele escreveu também um livro sobre os índios Tikuna (publicado somente em 1952), que moram lá na fronteira do Brasil com a Colômbia e com o Peru, onde o Rio Amazonas entra no Brasil. Nimuendaju, embora fosse alemão, possuía esse nome que ele ganhou dos índios Guarani, com quem ele trabalhou primeiro. Índios Guarani de São Paulo, que vinham do Paraguai ou do Mato Grosso à procura do mar. Então Nimuendaju ganhou esse nome deles e passou a assinar esse nome, sobretudo depois que ele se naturalizou brasileiro em 1922. Era o ano em que se comemoravam os cem anos da independência do Brasil, então parece que criaram condições para naturalizar mais facilmente os estrangeiros que aqui viviam. Nimuendaju aproveitou essa oportunidade para se naturalizar.

Pois bem! Foi Nimuendaju quem deu a conhecer ao mundo, sobretudo ao mundo acadêmico, a existência dos Timbira. Depois de Nimuendaju, então, outros pesquisadores começaram a se interessar também por estudar os Timbira. E foi o William Crocker, o Bill, o Pỳp (Poraquê), que começou os trabalhos em 1957. Ele estudou os Canela, dessa data até 2011. Ele passou mais de cinquenta anos estudando os Canela. Certamente ele ainda estuda em sua casa o material Canela. Ele sempre diz que gosta de estudar a língua Canela. Ao mesmo tempo em que o Crocker estudava os Canela, surgia outro projeto de pesquisa que misturava pesquisadores brasileiros com pesquisadores norte-americanos. Era um projeto que juntava o Museu Nacional, no Rio de Janeiro, com a Universidade de Harvard, nos Estados Unidos. Então, no
Museu Nacional, no Rio de Janeiro, selecionou-se, para pesquisar os Timbira, Roberto DaMatta e eu também. Roberto DaMatta estudando os Apinajé e eu, os Krahô. E também chegaram estudantes de Harvard que estavam fazendo doutorado para estudar os Timbira. Entre esses estudantes estavam a Jean Carter Lave e a Dolores Newton, que vieram estudar os Krikati e os Gaviões ${ }^{2}$ do Maranhão.

Bem, então eu trabalhei com os Krahô. Escrevi três livros sobre os Krahô (MELATTI, 1967; 1972; 1978). Um maior e os outros menores. Esses meus livros e meus trabalhos, vamos dizer assim, foram logo desafiados pelos trabalhos de duas pesquisadoras que vieram depois: Manuela Carneiro da Cunha e Maria Elisa Ladeira. Elas levantaram teses de maior abrangência explicativa quanto às relações entre 0 “nós” e os "outros” para os Krahô. Manuela, sobretudo, estudou as relações entre vivos e mortos, considerando que as pessoas ao morrer se tornavam "outros" (CARNEIRO DA CUNHA, 1978). Os mortos tornam-se uma espécie de não-parente, de outro. A ponto de, por exemplo, para sepultar os mortos, não vão os parentes sepultar os mortos, mas se chamam pessoas que não são parentes, sobretudo cunhados e genros, para cavar a sepultura e enterrar os mortos. Já Maria Elisa Ladeira deu uma explicação do parentesco Krahô que de certa maneira é mais satisfatória que a minha (LADEIRA, 1982). Eu não vou entrar em detalhes aqui porque isso tomaria muito tempo. Nisso, Maria Elisa Ladeira seguiu o exemplo de Roberto DaMatta, que no seu estudo sobre os Apinajé faz comparações com outras sociedades, inclusive os Kayapó (DaMATTA, 
1976). Maria Elisa Ladeira esteve com os Krahô e também com os Canela da Aldeia do Ponto, da Aldeia do Escalvado e também com os Apànjekrá da aldeia Porquinhos, considerando todas elas em seu estudo, fazendo um estudo comparativo. Eu não fiz estudos comparativos, fiquei só nós Krahô. Bem, a mesma coisa aconteceu com o Odair Giraldin, que fez reparos na etnografia de Roberto DaMatta e aprimorou o exame da relação entre casamento e transmissão da amizade formalizada entre os Apinajé (GIRALDIN, 2000). Também não vamos entrar em detalhes quanto a isso, pois levaria tempo demais e, sobretudo, porque eu não sei dizer essas coisas de cor. Para entender esse sistema complexo eu teria que voltar ao texto e acompanhar direitinho e eu não posso fazer isso agora.

Este Seminário que agora nos reúne, tem a participação de novos pesquisadores tanto não índios quanto pesquisadores Timbira. A presença de pessoas Timbira entre pesquisadores seria inimaginável na época em que realizei minhas pesquisas com os Krahô. Ou seja, quando eu comecei a minha pesquisa com os Krahô, em 1962, eles tinham uma população de mais ou menos quinhentas e vinte pessoas. Dentre elas, havia apenas três alfabetizados, mas não tão bem alfabetizados assim. Talvez o mais bem alfabetizado fosse Pedro Penon e havia outros dois que liam com dificuldade, mas liam. Eles não poderiam fazer um curso de graduação ou qualquer disciplina. Então, seria inimaginável! Ontem eu fiquei pensando: o que dirá o Roberto DaMatta quando souber que um Apinajé citou aqui neste Seminário o filósofo Jean Jaques Rousseau? Eu acho que se ele soubesse disso, ele te mandaria [Cassiano Apinajé] um livro de Tocqueville, de que ele gosta muito, para você continuar os seus estudos.
Eu achei todas as apresentações que se fizeram aqui muito interessantes e várias delas muito ricas e sugestivas, mas penso e aqui eu estou me referindo às apresentações dos Timbira - que nos futuros seminários elas devam ser não apenas descritivas, mas também críticas. É preciso levar em conta os autores anteriores que trataram do mesmo tema, mas não simplesmente para aceitar de antemão o que eles disseram. A gente não pode aceitar de antemão aquilo que os autores anteriores disseram como se correspondesse exatamente à realidade, à pura verdade. É preciso conferir a sua descrição e discutir a sua interpretação e explicação. Tal como Manuela Carneiro da Cunha e Maria Elisa Ladeira fizeram comigo. Ou como o Odair Giraldin fez com Roberto DaMatta. E também é necessário comparar um mesmo tema ou questão em mais de um povo Timbira. Ou seja, nas apresentações que se fizeram aqui, o que aconteceu é que quem é Apinajé apresentou alguma coisa referente aos Apinajé, quem é Gavião apresentou alguma coisa referente aos Gavião, quem é Krikati apresentou algo referente aos Krikati, e assim por diante. É bom que se compare. Por exemplo, houve apresentações relativas aos nomes pessoais, à transmissão dos nomes pessoais, ao significado dos nomes pessoais. Uma apresentação poderia comparar nomes pessoais em vários grupos Timbira e assim também com outros temas.

Enfım, o que eu queria dizer - e que talvez seja uma comparação não muito adequada - é que a gente pode comparar a atividade da pesquisa antropológica com a corrida de toras. Para se fazer uma corrida de toras é preciso ter duas toras pelo menos. Então nós podemos dizer que uma tora representa a descrição e a outra tora representa a interpretação, a explicação. 
Não basta ter a tora da descrição, é preciso também ter a outra tora, a da explicação. E os estudiosos e os pesquisadores são os corredores que vão carregando as toras. Aqueles que ficam cansados ou que estão velhos, eles vão se cansando e entregam a tora para quem vem atrás, que é mais jovem, mais forte e que continua a corrida, e continua desenvolvendo os estudos. E o velho, mais cansado, vai mais atrás ou correndo devagarzinho ou andando ou então se senta na beira da estrada e vê a tora passar. É assim, mais ou menos, que eu acho que funciona a pesquisa nas ciências sociais ou talvez nas outras ciências também.

É preciso fazer crítica! E para que os pesquisadores Timbira se exercitem na crítica eu vou distribuir, entre os Timbira que fizeram apresentações no Seminário, exemplares do meu velho livro Ritos de uma Tribo Timbira. Não é para tomá-lo como verdade. Pelo contrário, é para criticá-lo. Quem por ventura ler o livro deve se exercitar em fazer crítica. Eu mesmo faço até uma primeira crítica. Esse livro é um livro sobre ritos dos Krahô, não tem comparação com os ritos de outros grupos Timbira. Agora, ele é um livro sobre ritos, mas que não sabe cantar. Eu descrevo os ritos, quem faz, como é que se faz, como são os movimentos nos ritos, como se deslocam as pessoas que estão participando dos ritos etc., etc. Mas as músicas não aparecem. Então é preciso acrescentar as músicas e eu deixo isso para vocês. Essa é uma primeira crítica, é a tora que eu passo para vocês carregarem.

\section{Referências}

CARNEIRO DA CUNHA, M. Os mortos e os outros: uma análise do sistema funerário e da noção de pessoa entre os índios Krahó. São Paulo: Hucitec, 1978.
DAMATTA, R. Um mundo dividido: a estrutura social dos índios Apinayé. Petrópolis: Vozes, 1976.

GIRALDIN, 0. Axpên Pyràk: história, cosmologia, onomástica e amizade formal Apinajé. 2000. $296 \mathrm{f}$. Tese (Doutorado em Antropologia Social) - IFCH, Universidade Estadual de Campinas, Campinas, 2000.

LADEIRA, M. E. A troca de nomes e a troca de cônjuges: uma contribuição ao estudo de parentesco Timbira. 1982. Dissertação (Mestrado) - Universidade de São Paulo, São Paulo, 1982.

MELATTI, J. C. Índios e criadores. Rio de Janeiro: Instituto de Ciências Sociais - UFRJ, 1967.

0 messianismo Krahó. São Paulo: Herder, 1972.

Ritos de uma tribo Timbira. São Paulo: Ática, 1978.

NIMUENDAJU, C. The Apinayé. Washington, D. C.: The Catholic University of America Press, 1939.

The Šerente. Los Angeles: The Southwest Museu, 1942.

The Eastern Timbira. Berkeley: University of California Press, 1946.

The Tukuna. Berkeley \&t Los Angeles: University of California Press, 1952.

Recebido em: 19/06/17

Aprovado em: 16/11/17 